\title{
Institutional Isomorphism \& the Rise of a Hybrid Model in Education Philanthropy
}

\author{
Sara R. Sands \\ Department of Education Policy \& Social Analysis \\ Teachers College, Columbia University
}

For presentation at the American Political Science Association Conference, August 2019.

\begin{abstract}
While private foundation involvement in education has expanded significantly over the past three decades, their role and impact education policy has been largely under scrutinized. In particular, how foundations think about their impact and that of their grants, how they approach grantmaking in order to achieve their goals, and the impact such thinking has on other foundations across the philanthropic sector is largely unexplored. In this paper, I draw upon a theoretical framework informed by institutional isomorphism (DiMaggio \& Powell, 1983) to analyze the grantmaking practices of traditional and strategic philanthropies, with particular attention to areas of increasing convergence such as the utilization of measurable outcomes and metrics. Drawing from interviews with foundation officers at six philanthropies and grant data from Foundation Directory Online, I find that while differences remain between traditional and strategic philanthropies, a new "hybrid philanthropy" model is emerging that blends outcomesoriented and field-oriented approaches to grantmaking. I also find that the homogenization of practices across foundations and the influence of larger policy trends focused on data-driven decisionmaking may be leading foundations to exercise what might be termed "high stakes grantmaking." To the extent that this might conflict with what is good for students and communities, and the goals of democratic decision making in education policy more broadly, additional research is needed.
\end{abstract}

\section{Introduction}

Over the past three decades, the quantity, size, and scope of private philanthropies in the United States has expanded rapidly, yet their role and impact on public policy, has largely been under scrutinized (Hess \& Henig, 2015; Reich, 2016). Education, like many other areas of public policy, has long been a target of private philanthropy. A growing emphasis on the part of foundations to support national policy advocacy efforts has ushered in a new era of reforms propelled by philanthropic involvement, including implementation of value-added measures to teacher evaluation, whereby teacher quality is evaluated based on student test scores; the rollout of a longer instructional day and year with higher teacher compensation; the development and expansion of charter schools and other forms of privatization; and the commitment of governors to adopt a standardized curriculum and educational standard (Reckhow, 2013; Reckhow, 2016; TompkinsStange, 2016). Perhaps the most substantial area through which foundations can influence education policy is their grantmaking. However, relatively little research has been directed at how foundations undertake this core function, including how it continues to evolve and the influence such practices have on the field of education philanthropy. In 
particular, how foundations think about their impact and that of their grants, how they approach grantmaking in order to achieve the ends they believe to be most important, and the impact such thinking has on other foundations across the philanthropic sector are largely under-theorized.

In this paper, I draw upon a theoretical framework informed by institutional isomorphism (DiMaggio \& Powell, 1983) to analyze the grantmaking practices of traditional and strategic philanthropies, with particular attention to areas of increasing convergence such as the utilization of measurable outcomes and metrics. Most recent literature examines the ways in which traditional and strategic philanthropies differ in their approach to grantmaking (see Hess \& Henig, 2015; Reckhow, 2010, 2013; Scott, 2009; Snyder, 2015; Tompkins-Stange, 2016). Literature that does examine convergence of traditional and strategic foundations tends to focus on the funding of specific grantees and policy- and advocacy-focused activities (Reckhow \& Snyder, 2014; Snyder, 2015). The application of institutional isomorphism draws into focus the ways in which the grantmaking practices of traditional and strategic philanthropies inform and conform to each other, leading to "homogeneity of organizational forms and practices" (DiMaggio \& Powell, 1983, p. 148). As is the case with many organizations working in contested policy areas where political pressure to prove success is high but technologies are poorly understood, goals are ambiguous, and the context of policy implementation breeds uncertainty, foundations model themselves on each other to shore up their own legitimacy while attempting to mitigate said uncertainty (DiMaggio \& Powell, 1983). The end result is a field marked by likeness as opposed to variation, which has direct consequences when it comes to determining which policy problems and solutions, and subsequently organizations, are privileged and funded.

This paper begins with a broad overview of recent research on current philanthropic models and grantmaking approaches. I then move to discuss institutional theory, particularly institutional isomorphism, through which the data on foundation strategies and grantmaking practices are analyzed. Next, I apply the framework, using it to parse the data from interviewees to better understand in what ways strategic and traditional philanthropies converge and diverge in their approaches and orientation to key areas of grantmaking, including conceptualization of foundation impact, strategies to pursue desired outcomes, and application of measurable outcomes and metrics.

My analysis yields two new hypotheses. First, while there are indeed some clear differences between strategic and traditional philanthropies, there is reason to believe that a third hybrid philanthropy model is emerging. This third model reflects a blending of outcomes-driven and field-oriented approaches to grantmaking, balancing the centrality of selecting and achieving measurable outcomes alongside the desire invest in the organizational capacity of grantees as a means of building social and political change over time. In particular, it points to a shift across foundations towards thinking about grantmaking in terms of supporting the growth of systems or ecologies of organizations working towards certain policy outcomes and away from supporting programs or singular organizations. Second, the homogenization of practices across traditional foundations and strategic philanthropy models and the influence of larger policy trends focused on identifying measurable outcomes may be leading many foundations to exercise what might be termed "high stakes grantmaking." High stakes grantmaking suggests that foundations make grants based on the ability of grantee organizations to set and reach 
high achievement measures and preference grant renewals to organizations that meet those measures. Such grantmaking is high stakes because grantees, in order to obtain funding, must appear to have and be able to track and reach measurable outcomes, and then achieve those outcomes once funding is obtained. The implications of this are manifold, as it could highly restrict what policy problems and solutions grantees deem as valuable to pursue based on whether grantees believe they can measure the outcomes of a proposed solution and reach the goals determined in the grant agreement. To the extent that this might conflict with what is good for students and communities, and the goals of democratic decision making in education policy more broadly, additional research is needed.

\section{Current Philanthropic Models and Grantmaking Approaches}

Considering the philanthropic landscape, there are generally thought to be two kinds of foundation models. The longer-standing model is that of traditional philanthropy. Traditional foundations emerged in the early 20 th century, founded by wealthy industrialists and their families who had numerous goals, including influencing public policy and social investment outside the scrutiny of government as well as providing support for the development of institutions beneficial to their conception of the public good (Scott, 2009). Foundations typically associated with this model are those like the Ford Foundation, the W.K. Kellogg Foundation, and the Carnegie Corporation of New York. Undergirding this model are "field-oriented" approaches to grantmaking, which can be defined as "efforts to build, support, or transform existing or new organizational fields through investing in organizations' capacities to pursue social change over a long period of time" (Tompkins-Stange, 2016, p. 55). The use of fieldoriented approaches in managing grantees, selecting partners, framing problems, and evaluating results has a number of implications. These include: 1) selecting partners that are predominantly operating at the grassroots, community level; 2) framing adaptive problems that are more complex and multifaceted with less clear solutions; and 3) evaluating program results using a mix of qualitative and quantitative metrics, inviting evidence that is harder to measure (Tompkins-Stange, 2016).

The second model is that of strategic philanthropy, which emerged in the late 1990s. Leveraging the vast fortunes of typically living benefactors, strategic philanthropy is characterized by its emphasis in investing in disruptive change and building momentum around those change makers who show the highest, most promising results (Hess, 2005). The goal of these foundations is interpreted as aiming to set up proof points of what works with the goal of scaling those models beyond the initial investment to achieve even higher outcomes (Russakoff, 2016). The Eli \& Edythe Broad Foundation, Bill \& Melinda Gates Foundation, and Walton Family Foundation are each associated with strategic philanthropy. Underpinning this model are "results-driven" or "outcomeoriented" approaches to grantmaking, which can be defined as "efforts to achieve goals that are determined at the outset of an initiative and measured by indicators that grantees are held accountable to" (Tompkins-Stange, 2016, p. 55). The use of outcome-oriented approaches in managing grantees, selecting partners, framing problems, and evaluating results has its own set of implications, including 1) selection of organizations that are more inclined to work with elite or "expert" organizations at the "grasstops" level; 2) pursuit of problems for which there exist technical solutions and a clear line of causality 
between them; and 3) evaluating problems using quantitative metrics that more neatly show impact (Tompkins-Stange, 2016).

The large majority of research focuses on the divides between traditional and strategic philanthropies (see for examples Hess \& Henig, 2015; Reckhow, 2010, 2013; Scott, 2009; Snyder, 2015; Tompkins-Stange, 2016). In her analysis of the politics of strategic philanthropy in charter school policy and advocacy, Scott observes that there are distinct language patterns and philosophies that separate traditional philanthropies from strategic philanthropies (2009). Specifically, strategic philanthropies utilize "market language for social exchanges"--“"grants become investments, programs are strategics and measures of impact generally involve the ability to scale up an initiative" (Scott, 2009, p. 115). However, there is reason to believe that there are growing similarities between traditional and strategic foundations, particularly when it comes to approaches to grantmaking. First, research indicates that traditional and strategic foundations may be converging in the funding of specific grantees, which could indicate convergence in the area of policy-focused and advocacy-focused philanthropy. (Reckhow \& Snyder, 2014).

Second, Reckhow, in her work on tracing the influence of foundation dollars on education policy, also identifies contributing factors that have enabled all major education grant makers to court a more public role and yield greater policy influence, including that major foundations have tried to emulate business practices and develop more selective targeted grantmaking strategies (2013). While Reckhow acknowledges that the move to "results-oriented giving" is largely associated with strategic philanthropies like Broad, Gates, and Walton, she notes that it has come to serve as a common framework among foundations writ large. This subsequently signals that foundation leaders across the board have developed higher expectations for the output of their grantmaking, including major policy change and measurable outcomes, perhaps pointing towards an area of convergence. Finally, the expanded use of management consultants and collaborative roundtables across the foundation sector not only further demonstrates the preoccupation with using business strategies and proving effectiveness of grantmaking, but also the promulgation of these beliefs across different types of foundations (Reckhow, 2013).

This emphasis on areas where foundations typically construed as different and divergent might be viewed as increasingly similar is crucial to this analysis. As I will elaborate upon in the following section, DiMaggio and Powell (1983) note that "much modern organizational theory posits a diverse and differentiated world of organizations in structure and behavior" (p. 148). However, the widespread adoption of business-like practices, including utilization of measurable outcomes and metrics, growing emphasis on policy-focused and advocacy-oriented philanthropy, and increasing expectations of what grantmaking can achieve indicate a level "of homogeneity of organizational forms and practices” (DiMaggio and Powell, 1983, p. 148) heretofore overlooked.

\section{Elements of Institutional Theory}

The story of the modern foundation might be seen as the story of organizational evolution in the context increasing institutional and technical demands. Meyer, Scott, and Deal (1983) define institutionalized organizations as those that "closely integrate their own structural arrangements with the frameworks established by the larger institutional structures" (1983, p. 46), meaning they work to emulate and embody the normative rules 
and processes of their field in order to gain legitimacy. Such organizations contrast with those that are more technical, meaning that they are designed to achieve specific outcomes through a standardized set of procedures, and thus, their structures are intended to regulate said flows, shield them from uncertainty, and protect them to some degree from external sources. Where the technical organization turns away from the environment to protect coordinative structures, the institutionalized organization turns away from the technical aspects to focus on molding to its institutional environment (Meyer et al., 1983).

At first glance, foundations appear to be solely technical institutions. In the education philanthropy literature, foundations appear to be organizations that are committed to rationally organizing their internal work processes to achieve a set of performance outcomes: setting a logical division of labor, clarifying work procedures, and coordinating the entire system to ensure achievement of measurable outcomes (Sands, 2019). However, to focus solely on these operational aspects would be to ignore the ways in which core foundation practices are in large part consistent with one another, reflecting a bias towards "conformity to the normatively held rules of scripts of the institutional environment" (Huerta \& Zuckerman, 2009, p. 414). In the case of foundations, the institutional environment designates legitimate ways of "doing philanthropy." As such, foundations are simultaneously subject to technical and[ institutional demands, balancing technical pressures to meet strategic goals and institutional pressures to conform, most notably through the adoption of business practices, including the utilization of performance measures.

With respect to increasing institutional pressures, DiMaggio and Powell's (1983) theory of institutional isomorphic change provides a useful framework to explore the extensive homogeneity across foundations that results from institutional pressures. DiMaggio and Powell observe that, particularly in a competitive environment, the structuring of organizations into a field leads eventually to them become increasingly similar. By organizational field, I use DiMaggio and Powell's definition meaning "those organizations that, in the aggregate, constitute a recognized area of institutional life" $(1983,148)$. By limiting the range of choices individuals can make and still appear competitive and legitimate, highly structured organizational fields offer a context "to deal rationally with uncertainty and constraint" (DiMaggio \& Powell, 1983, p. 147). However, in the long term, the limits as to what strategies and actions are considered legitimate leads "to homogeneity in structure, culture, and output" (DiMaggio \& Powell, 1983, p. 147). DiMaggio and Powell use the term "isomorphism" to describe the process through which one entity in a population is forced to resemble other entities that operate in the same set of environmental conditions. They describe three mechanisms through which isomorphic change happens: 1) coercive isomorphism, which results from formal and informal pressures, particularly political influence and the need to appear legitimate by society, that organizations exert on other organizations on whom they rely; 2) mimetic isomorphism, which derives from organizations that operate under conditions of uncertainty modeling themselves on other organizations; and 3) normative isomorphism, which comes from professionalization, spurred on by formal education and the legitimation of specific knowledge on the one hand and the rapid expansion of crossorganizational professional networks on the other (DiMaggio \& Powell, 1983). 
While foundations are not competitive in an economic sense, there are other resources for which foundations can compete, including political power and institutional legitimacy (Tompkins-Stange, 2013). As foundations are modern organizations equally interested in those markers of social fitness, institutional isomorphism provides a useful tool for understanding them. Specifically, many foundations, confronting a field marked by increased adoption of business-inspired practices and utilization of metrics and measurable outcomes, yield to isomorphic pressures in order to maintain their legitimacy. Furthermore, to the extent that education itself is a complicated field, vexed by uncertainty, unclear goals, and poorly understood technologies, education philanthropy must contend with these realities while seeking to confirm its own legitimacy, thereby exposing itself to greater isomorphism (DiMaggio \& Powell, 1983). Importantly, isomorphism does not preclude organizations from changing their goals or adopting new practices, presumably under the pretense of rationality. Rather, it suggests that over time, strategies that might be rational when one organization adopts them may not be rational if increasing numbers adopt them, even though their normative sanctioning makes them more likely to be adopted. As becomes evident in the convergence analysis, there many be long-term consequences of the spread and codification of some grantmaking practices over others, including a decreasing variety of organizations receiving grants.

\section{Methods and Data}

This study draws from a theoretical paradigm that centers the construction of knowledge through participants' experiences (Merriam, 2009). To center the experiences of participants, I undertook semi-structured, open-ended interviews lasting approximately 60 minutes with 10 foundation officers from six different foundations active in funding K-12 education and a pair of consultants to those foundations. All foundation officers were at similar structural levels within their respective organizations and included a mix of program officers, evaluation officers, and grants managers. In order to consider foundations of different sizes and those funding at both the national and local level, I selected foundations that funded organizations in the same major urban school district from 2010 to 2016, a district that has a very active local funding community in addition to attracting investment from foundations with a national scope. I also selected foundations that represent a mix of strategic and traditional philanthropy, and have a range of endowment sizes and investment levels in education. All interviews were coded with a mix of deductive and inductive approaches, starting with the creation of an initial coding list based on the key themes of the interview questions, followed by comparing selections to properties of the category, and then refining and reconceptualizing the categories with each subsequent iteration (Merriam and Tisdale, 2016; Charmaz, 2006). Given the sensitivity of the information respondents provided, the names of the foundations and the participants have been kept confidential, as well as the names of grantees, where requested.

Table 1 shows an overview of select characteristics of each foundation and Table 2 provides an overview of the number of grants, grant recipients, and total grant dollars each foundation made in the area of elementary and secondary education from 20102016. The Appleton Foundation and Birchwood Foundation are both national independent foundations with endowments stemming from the significant personal fortunes of their living benefactors who amassed their wealth through business. The 
Crescent Foundation, which operates solely in a large urban area in the Northeast and is significantly smaller than Appleton and Birchwood, is similar to them in that its trustees, like foundations with living benefactors, are actively involved in contributing money to the fund and directing its grantmaking activities. As such, Appleton, Birchwood, and Edwards represent strategic philanthropies. Silverstone Foundation and Tanner Foundation are large national independent foundations, founded in the early 1900s by men who earned their fortunes in industrial-era manufacturing. Finally, Vance Trust is a community foundation founded by leaders in the banking sector in the $1920 \mathrm{~s}$ with the purpose of managing and dispensing funds raised through charitable trusts. Vance solely serves the same large metropolitan area as Crescent. While Vance is different in terms of operating structure from Silverstone and Tanner, I consider it representative of traditional philanthropies in this analysis given its founding in the early $20^{\text {th }}$ century.

In addition, I build on earlier literature identifying convergence in funding by illustrating the pattern of convergence between strategic philanthropies and traditional philanthropies. For this analysis, I use publicly available information from Foundation Directory Online, taken from 990-PF forms and other means of foundation reporting, to show where homogenization of grantmaking practices may be leading to homogenization of the grantee pool and, ergo, solutions to policy problems. I searched for all grantees receiving grants focused on early childhood education, education services, educational management, elementary and secondary education, and equal opportunity in education from 2010 to the 2016 . The final dataset contained 10,409 grants, totaling over $\$ 4.7$ billion with 3,122 different grantee organizations. To identify patterns of convergence, I manipulated the dataset to identify grantees that had received grants from at least two of the six foundations, with at least one grant being from a traditional foundation and one from a strategic foundation. This brought the list to 273 organizations. For a grantee to have a high-level of convergence, it had to have at least four points of connection, with at least two grants from traditional foundations and two from strategic foundations. This brought the list to 28 organizations. While this is a small number of organizations, the strong similarities across them has the potential to shed light on what types of organizations might receive funder preference in emerging models.

\section{An Emerging Hybrid Model of Education Philanthropy}

While the interviews I conducted highlighted continued differences in the ways that traditional and strategic philanthropies operate that align to existing literature, they presented numerous instances of institutional conformity. In particular, convergence emerged in three key areas: adoption of business practices, including utilization of the concepts of theory of change, measurable outcomes, and metrics; emphasis on building organizational and field capacity; and advancement of strategic learning in grantmaking. The bi-directionality of this movement is notable as it is not just traditional philanthropies that seem to be adopting the discourse, including the mindsets, language, and practices, of strategic philanthropies, but also in some cases strategic philanthropies adopting the discourse and practices of the older, more traditional foundations. This suggests the emergence of a hybrid model of education philanthropy characterized by a combination of outcomes-oriented and field-oriented grantmaking, with foundations trying to balance

a desire for control and causality (both between problems and solutions and their funding 
and observed changes) with a desire to address complex, multifaceted problems utilizing the expertise of those on the ground.

\section{Business Matters}

The adoption and expansion of business practices, specifically articulation of a theory of change and identification of metrics and measurable outcomes, is a prime example of the homogenization predicted in coercive isomorphism, and the movement of traditional philanthropies towards practices associated with strategic philanthropies is the first area that indicates the emergence of a hybrid model in education philanthropy. As coercive isomorphism suggests, "organizations are increasingly homogeneous within given domains and increasingly organized around rituals of conformity to wider institutions" (DiMaggio \& Powell, 1983, p. 150). In that regard, professional sectors might come to impose on themselves standard operating procedures and normative rules and sanctions that support the homogenization of organizational models. In the case of the foundations interviewed, both processes were linked to the "theory of change" or "theory of action," which can be best defined as "an articulation of the results an organization must achieve to be successful, and how it, working alone or with others, will achieve them" (Forti, 2012). As we would expect based on existing research, theory of change - a key marker in strategic planning in the business sector-plays a central role in selecting grantees and designing grant proposals in strategic philanthropies. The remarks from a senior foundation officer at Birchwood illustrate as much:

When we enter into a conversation with the potential grantee, we start off with a conversation about potential alignment between the grantee goals and the foundation goals and then once we see that there is alignment, if we see that there is alignment, we would then invite them to submit a formal proposal and as a part of that process they generate a series of outcome performance measures which are intended to reflect the theory of change of the grant, which is to say how change is supposed to happen, what are they going to do and what do they expect to result from that.

Reflecting institutional isomorphism, traditional foundations also leaned heavily on the importance of alignment between the theory of change of grantees and that of the foundation when it came to selecting grantees and setting up the grant parameters. Multiple informants from Tanner talked about the importance of "the coming together of ideas, institutions and individuals" in grantmaking, emphasizing theory of change as a way to align around ideas. A program officer from Tanner went into greater depth, focusing on the importance of the foundation's theory of change in grantee selection:

We definitely ask about their own organizational theory of change, in addition to their organizational strength. There's an early stage conversation where we ask, "Is this philosophically aligned? Does it fit in our grant making parameters?"

This was echoed in other ways by one of the foundation officers at Silverstone, who stressed the importance of articulating alignment between the theory of change of the grantee and that of the foundation to senior officers and decision makers, including 
the President and the Board of Directors, as part of the grant approval process. Remarks from foundation officers at Tanner and Silverstone suggest that growing emphasis on theory of change in the practices of traditional foundations may be linked to the widespread use of management consultants and other evaluation organizations. In the case of Silverstone, one foundation officer noted that consultants were often called upon to help craft a theory of change and provide recommendations as to how to pursue it, and later called back to evaluate progress towards that theory of change and its goals. In the case of Tanner, participation in roundtables with other foundations and use of evaluation firms specific to philanthropy is common practice. To that end, we might think of consultants and evaluation firms as providing a means of diffusion of practices from one organization to another, thereby facilitating the process of mimetic isomorphism, wherein organizations come to mirror each other in an effort to tackle similar uncertainties and problems, subsequently advancing homogeneity across the field.

Of course, as predicted by institutional isomorphism, differences in both policy and strategy within organizations remain (DiMaggio \& Powell, 1983). This can be noted in how the different foundations orient towards theory of change. While both kinds of philanthropies clearly believe in aligning grantees to their theory of change, the importance of measurement to that process varies greatly. The comments from the program officer at Tanner suggest that the theory of action of the grantee organization in it of itself is what is worthy of funding and that alone is enough to make it a funding priority, irrespective of metrics. In the case of Birchwood, the ability to assess a grant to prove ones theory of change is primary. What the grantee can accomplish and how it intends to do so, and aligning both those things to the theory of change of the foundation, is what warrants funding. Nevertheless, given the high degree to which uncertainty and goal ambiguity prevail in education, the adoption of shared language to rationalize decision making across foundations funding educational change may be seen as a means to generate a sense of control.

In addition to a growing shared reliance on structuring the selection of grantees and creation of grants around theory of change, the emerging hybrid model of education philanthropy is marked by extensive adoption of measurable outcomes and metrics in grantmaking practices. Answers from respondents about measurable outcomes and metrics indicated that there are essentially three kinds of metrics. One sort of metric is best likened to an "output" or a "deliverable." For example, "did a grantee write the number of reports it said it would," or "did the grantee hold a convening when it said it would". These are easily quantifiable and, as such, perhaps the most accessible to assess success of a grant. Another sort of metric is a performance-based metric. Performancebased metrics attempt to quantify the changes of capabilities, mindsets, and behaviors as a result of grant activities. Examples of these might include student achievement, teacher effectiveness, or high school graduation. Finally, a third type of metric reflects qualitative assessments focused on evaluating changing conditions of the field. These field-based indicators try to ascertain if and how grant activities are influencing the environments in which grantees operate, including policies, policymakers, other key stakeholders, relationships between different groups, whole sectors, etc.

All the foundations interviewed relied on the three different types of metrics in their grantmaking practices, albeit to varying degrees. On a basic level, all foundations utilized deliverable metrics to ascertain whether grantees fulfilled the activities of the 
grant (e.g. did the grantee host professional development sessions, create and disseminate materials to policymakers, host convenings, etc.) The use of performance measures was also widespread. Across the grant applications and grant processes referenced by both traditional and strategic philanthropies, performance measures were a central component. Unsurprisingly, strategic philanthropies articulated a strong interest in quantifiable performance measures such as, for example, student test scores, attendance rates, school graduation rates, teacher performance ratings, and program satisfaction rates. On the traditional side, Silverstone expressed the strongest interest in performance measures, echoing similar statements from strategic philanthropies that while quantitative measure are not everything, they serve a central role in determining initial and subsequent grant funding. Even smaller traditional foundations like Vance noted that as the amount of money to education grantees has increased, so too has the expectation that the grantees articulate, track, and achieve more substantial performance measures.

The proliferation of high performance measures represent one way in which strategic philanthropies seem to be influencing traditional philanthropies, while the tempering of these metrics with an awareness of the history of grantees and the context in which they operate reflects a way in which traditional philanthropies may be influencing strategic ones. These remarks from a program officer at Birchwood indicate the centrality of understanding the grantees' perspective of what is happening on the ground level when engaging in metrics selection, evaluation of grant success, and determination of future funding:

The whole metrics process and definitions of success is led by the grantee because they are the ones on the ground doing the work. We're just there to learn the work. Whether they meet a metric or not, there's a conversation to be had to see how they're doing and we would get reports on it, but ultimately it is just to guide the discussion.

This lines up with similar statements from a program officer at Silverstone: Level setting about what the right metric is, or what the right value is within a given metric, has been a product of a long conversation with the grantee about what they've experienced historically, what the trends are, how ambitious their work this year is, and what they're changing, including whether they believe it should be more impactful and, if so, how much more impactful.

Taken together, these reflections tell an interesting story about homogeneity with respect to selection and evaluation of metrics and potential hybridity. Assuming them as representative of their different subgroups, the comments from the program officer at Birchwood reflect a growing awareness of the importance of context in decision making around selection of metrics. On the other side, the comments from the program officer at Silverstone indicate a movement towards using metrics to gauge success of grantees that are reconciled with limitations of the grantee and the field. Other statements from the program officer at Tanner point to a balance of the two, emphasizing "the frame of the grantee in the driver's seat," who would steer the conversation with respect to what is the right measure of success, with the foundation providing input to ensure alignment with organizational goals and a few metrics valued by the foundation. 
Returning to isomorphism then, there is reason to believe that in both instances, the adoption of practices by both types of philanthropy typically characterized as belonging to the other type suggests adaptation, likely as a means to increase the effectiveness of their organizations (DiMaggio \& Powell 1983). Indeed, across the board, foundation officers expressed deep concerns about how they might be more thoughtful in their grantmaking practices in order to be more effective at achieving the type of changes in education that they valued. That there is at least the perception of a finite range of choices that foundation actors might perceive as rational or prudent (e.g. utilize more performance measures, assign greater weight to contextual factors that impact grantees) to adopt in the name of effectiveness suggests that foundations are bound in some part to institutional demands that dictate appropriate options (Meyer et al., 1983).

This, again, is not to say that there do not remain significant differences in the field with regard to how different foundations orient towards metrics. The importance of factoring in the context in which grantees work--"the ecosystem in which they operate," as a Tanner program officer put it, including the presence of actors and what the foundation can contribute that would be meaningful to that environment - is fundamentally different between different kinds of foundations. This was most noticeable in how different foundations connected the fulfillment of foundation objectives to the selection of grantees and grant accomplishments. From the perspective of the strategic philanthropies in the sample, there was a tendency to define their objectives first and then seek out organizations that can carry out the work to achieve those objectives. It is at the point of proposal conception that the state of affairs on the ground becomes a factor. On the side of traditional foundations, the state of affairs on the ground determined what strategies they should pursue from the get-go, including to which areas to direct funding, whom to fund, and what success would look like. This leads to different understandings of the value of measurement and how the success of the organization can be measured and attributed to the work of grantees, as demonstrated by these remarks from the senior foundation officer at Birchwood and the senior foundation officer at Tanner:

Senior foundation officer, Birchwood:

So for example, if we set targets for the improvement of charter school policy across a number of locations, then we can count objectively, we can assess the amount of improvement, that there has been in policy and we can say: If we are working in 10 primary locations, then we want to see over a five year period $x$ amount of improvement in charter policy, which we think we can get given the level of investment that we have and the capacity of the partners in each location. We can pretty objectively assess that improvement and come up with an informed view of whether we think we have contributed to that. That would be a strategy level goal, a strategy of improving policy, particularly in the charter space, that has multiple actors, some of whom we fund, and we can link back down to the grant level metrics and see if we have funded organizations that are influencing the policy process. So that's how you see a pathway from an individual grant, across a body of grants, in service of a strategy level goal.

Senior foundation officer, Tanner: 
I think both the field of evaluation and philanthropy had a heyday of metrics and frankly, at that time, also a focus on somehow impact being understood at the individual grantee level. I think we could write a lot of apology letters to all those organizations we asked to build up their evaluation systems to count things which may or may not have been the best use of their time. At the time, what we [at Tanner] wanted was really rigorous evaluations of individual projects. I think as our philosophy of grantmaking has changed and our philosophy of how change happens has changed, we have become much more systems-focused and need to think of our grantees less as individual units and more as part of a larger set of actors that ultimately influence change. In that sense, any one individual's specific metrics become less important than how the field works together.

The contrast here, as previously noted, is stark, reflecting fundamental differences in how foundations believe they can trace the individual grantee measures to grant impact to overall foundation impact. Appleton, Birchwood, and, to some degree, Crescent all seemed to articulate a belief in the ability of the foundation to set a short list of goals to achieve through their grantmaking, to find grantees to fulfill those goals, and to carefully craft measures for each grant that, when examined as a collective, could be rolled up to gauge the foundation's impact. Silverstone, Tanner, and Evergeen were less concerned about the impact of any single grant, and more interested in the field-based indicators. Their focused seemed to be on the improvement of contextual factors - or instance were more stakeholders, policies, practices, and behaviors changed, as a result of grantee efforts.

That being said, even here, the impact of institutional isomorphism and growing homogenization can be observed. Reflecting the belief of strategic philanthropies, the informants at Silverstone believed that while the foundation was not there yet, they could possibly start to look beyond just a single grant and connect the impact of the foundation to the outcomes of all their grants, provided both the foundation and grantees had access to better measurement tools. This was particularly true at the program level, where program officers intimately aware of the work of each grant could assess their impact as a whole, provided the foundation goals in a particular area were nuanced enough so that the evaluation of impact could be limited to the foundation's and the grantees' loci of control. On the other side, the program officer at Crescent expressed a desire on the part of the foundation to not see their funding strategy and impact as limited to just the measures, particularly performance measures of a single grantee. Indeed, like traditional foundations, the respondent at Crescent reflects similar nuance here:

If the goal of the portfolio is to support high performing schools or organizations, these [metrics] are to determine that they are high performing. Right? But it is not like we have a specific bar that everybody needs to clear to be a high performing organization because the context is different. When we ask for things it isn't necessarily about how we are measuring our own success. We wouldn't measure our success based on individual grantee test scores. We want to know how our grantees are doing compared to the city on a whole. The state tests scores are the easiest to look at and say all the Uncommon Schools outperform 
their community test score by $x$ amount but that's not necessarily a reason to fund a particular organization.

As the findings so far indicate, the reconciling of technical expectations specific to each foundation alongside institutional demands, most notably the spread of business practices and utilization of measurable outcomes, is leading to growing homogeneity in terms of the grantmaking practices of strategic and traditional philanthropies. To be sure, clear differences in philosophy remain, particularly with respect to how much weight to assign to measurable outcomes when evaluating both the impact of grants and the foundation. However, as predicted by institutional isomorphism, particularly mimetic isomorphism, the trend seems to be for foundations to respond to uncertainty in the field by selecting from a limited menu of practices those that appear to have helped other foundations in achieving their own goals. The widespread adoption of these business practices is having a transformative impact on foundation models and feeds into the emergence of a hybrid model on the sector.

\section{The Field as an Ecosystem}

As the earlier discussion started to address, a key part of hybridity is the balance between outcomes-driven approaches and field-oriented approaches to grantmaking. While the emphasis on theory of change and achievement of measurable outcomes across most foundations suggests a hybrid model that is strongly oriented around the practices of strategic philanthropy, there is reason to believe that homogeneity is increasing as a result of field-oriented approaches to philanthropy as well. For instance, despite the strong focus on measurable outcomes initially expressed by respondents from Birchwood, further remarks from one program officer harken to a field-oriented approach:

We're looking to invest in strong leadership, which is demonstrated by experience in the field, in the sub-field, and demonstrated by the clarity and the feasibility of the plan. We're asking questions about the capacity of the organization to pull it off...the feasibility goes both to the ambitiousness of it and also what capacities exist at the organization.

While the program officer's remarks are still focused on the quality of measurable outcomes, what begins to come through is a desire to consider the strength of the organization and their field experience as an indicator for whether the organization itself can operate in the field and the foundation can decentralize control. Moreover, this trend on the part of outcomes-oriented foundations to emphasize funding organizational capacity to support organizations to be successful manifests on a more local scale as well, as indicated by the program officer from Crescent:

I think it [the foundation] wants to strengthen the nonprofit field and strengthen the fields that it funds as a whole in [the city]. It would love to see more organizations adopt the most successful practices of the organizations that we fund, but it isn't necessarily about moving toward a specific policy objective or specific practice objective. I think there is an understanding that there needs to be 
a lot of different models and kinds of organizations especially in education for all students to have places to grow and feel good.

This desire to not just strengthen the field but to nurture a pluralism of organizations that contribute to the achievement of broader systems change mirrors similar statements from a program officer at Tanner, who emphasized the importance of supporting a range of organizations intimately connected to an issue to ensure fulfillment of the foundation's objectives:

We consider ourselves an ecosystem grant maker. In this example, let's center youth organizing as the animating focus. Around youth organizing, there's a bunch of surrounding infrastructure that social movements need to be successful. So, even if organizing is at the center of social movements, there needs to be research infrastructure, legal infrastructure, storytelling infrastructure etc. We have to be proactive about asking what is the ecosystem that's required, is there a gap in that ecosystem, and is that a gap that we need to fill.

Of course, there remains the question in the cases of Birchwood and Crescent of what is a strong model and how do you determine that. One could argue that in these instances, what makes a model strong and worthy of funding to begin with is gauged by the results the organization has or can achieve against an explicit and discrete set of measures. That being true, it is no less the case that these responses indicate that these foundations, which are typically more outcomes-oriented and pursue an approach that hinges heavily on identification of measurable outcomes, metrics, and achievements of those metrics as indicative of organizational strength, are moving toward a model that recognizes the importance of funding capacity-building and strengthening organizations to do the work. This reflects the comments from field-oriented foundations such as Silverstone, Tanner and Vance, which emphasize funding organizations to carry out their individual theories of change as an important end goal in and of itself. In short, there appears to be explicit awareness of the need to fund the activities that explicitly lead to the attainment of stated goals and objectives, and to provide support to organizations to grow and strengthen their own operations in order to more effectively engage with others in support of the longer mission.

Blending of the traditional and strategic philanthropy models is further illustrated in how both these institutions think about how they grant funding to achieve specific objectives while at the same time building the capacity of the field. These reflections from the program officer at Appleton indicate that developing a sense of community and connectedness to influence systems change may be just as important as defining objectives and metrics:

These districts went through an RFP process where we actually paired them with consultants from McKinsey, $B C G$, and Parthenon, over a three months process to help them develop the RFP for their proposal. We also brought the districts together three times over that three month process to share what they were learning and doing in their proposals in the hopes that by creating this community, the proposals would be higher quality. 
Putting aside once more the continued emphasis on business practices and stewarding grantees towards the knowledge of management consultants, there is also an emphasis here on connecting grantees in similar circumstances to each other so they and the field might benefit from their collective knowledge. This sort of desire to get down to the local level and let the experiences of those local entities determine, at least to some degree, the grantmaking process, including proposal creation and selection of measurable outcomes, is typically something that is characteristic of traditional philanthropy, as exemplified by these remarks from the program officer at Vance:

[We are] thinking more about stretching limited dollars for maximum effect on a system as opposed to on a set of kids. We are driven by folks on the ground with direct contact with the public schools and are committed to letting them drive the agenda as opposed to funders having a set of things we want to accomplish.

This subsequently represents another part of hybridity in foundation models, which is shaped by the field-oriented approaches of traditional foundations. Though less pronounced than the influence of outcomes-driven approaches, systems change through ecosystem thinking, capacity building, and knowledge sharing across related organizations is starting to emerge in the thinking of strategic philanthropies. This, as previously mentioned, may be indicative of a growing emphasis on the importance of context to the success of foundation initiatives but also may indicate a much more significant shift across all foundations to think of policy reform as driven by ecological factors. As the program officer from Silverstone frames it:

Sometimes we talk about impact or scaling our impact instead of just saying "scale" because I think scale for a lot of people connotes a sort of replication paradigm. If we want this work to not only be high quality but to be sustained, it can't be through a replication paradigm. It has to be authentically developed in ways that are appropriately responsive to local context.

This implies that an explicit awareness of ecological factors specific to the local context is needed to be successful over the long term and to see preferred programs and policies be maintained beyond the grant term. Thus, within the hybrid model, this acknowledgement of the adaptive nature of problems comes into sharper focus, even if for some organizations the solutions remain technical. Relatedly, hybridity might be found in the ways that both strategic philanthropies and traditional philanthropies view their success as related to policy influence across a wide swath of actors on the ground. Compare again the discussion from the program officer at Appleton to the remarks from Vance:

Appleton:

The key metrics focused on examining if districts were shifting that curve to the right. There are different ways in which a district can achieve that: 1) They can improve the way they recruit, hire and train incoming teachers; 2) They can do a better job of retaining the most effective teachers and to increase their impacts 
amongst peers; 3) You improve your teacher evaluation system and teacher support systems and professional development and you move the big middle, and; 4) You make hard decisions around the bottom end of the curve, either you have them improve or you get them out of the system. A fifth related metric is how do you ensure that the kids that need it the most have the most consistent access to at least the top quartile of teachers, which, from what we were seeing, wasn't happening.

Vance:

The City's education budget is $\$ 22$ billion a year, although some of that is for pension costs. But you are talking about \$16-20 billion to run the schools. Philanthropy can't exert enough real financial influence in a system that large, so you are better off influencing how the system spends its $\$ 22$ billion than spending private dollars to get a certain thing done.

These remarks show a convergence on the part of both traditional and strategic philanthropies to see a primary objective of their work as influencing policy across a spectrum of actors to ensure that the types of actions they believe are needed to achieve their vision of change are taken. While this convergence has been well documented (Reckhow \& Snyder, 2014), the centrality of this belief to both types of philanthropies, not just strategic philanthropies and those traditional philanthropies that happen to fund similar grantees, indicates that it might be part of a wider shift and a feature of the new hybrid model. From an institutional isomorphism perspective, this might reflect a yielding on the part of the organizational field to mimetic pressures. Specifically, the growing ubiquity of field-oriented approaches, or at least an awareness of the need to account for the field in grantmaking processes, suggests a spreading belief of the legitimacy of such practices and their success in helping other foundations achieve their goals (DiMaggio \& Powell, 1983).

What is important to recognize here is that this shift is far from cemented. Most notably, the way these foundations continue to make sense of what can be and should be measured and, subsequently, what can and should influence decisions around funding do not always converge. However, there is evidence, as demonstrated here, of movement on the part of the strategic philanthropists to seek more middle ground, with the language and grantmaking approach evolving to, in a sense, take into account those that came before. This seems to include an explicit awareness that myopic focus on results, intolerance for longer-term timelines, and overly high expectations for quantification and measurement, may not be the best approach when trying to solve complicated public policy problems plagued by uncertainty and poorly understood technologies (TompkinsStange, 2016). On the other hand, while traditional philanthropies might appear on the surface committed to a philosophy that is agnostic to market approaches, they are nonetheless permeable to the philosophies and modus operandi of the strategic philanthropists, including shifting within their older frameworks to focus on "return on investment," "scalable models," "theory of change," and "financial sustainability," whether or not they officially adopt such terminology. As such, the adoption and embedding of strategic philanthropy approaches to grantmaking into traditional 
foundation enterprise and vice versa leads to a hybrid philanthropy model that fuses together the emphasis on capacity building and limited adherence to attainment of hard metrics of traditional philanthropies with the demand for clear understanding of impact and alignment of strategic objectives of strategic philanthropies.

\section{The Rise of High Stakes Grantmaking?}

While the hybrid philanthropy model proposed here seems to equally draw from field-oriented and outcome-oriented models of grantmaking, there is reason to believe that outcome-oriented approaches might continue to wield a stronger influence on the field and factor more heavily in the hybrid model. Based on the interviews conducted as part of this study, this influence seems to stem from a desire to prove causality and assess how the foundation and its grants, as informants at both Silverstone and Appleton put it, "moves the needle." This concern over accountability - specifically that the foundation can be seen by internal and external stakeholders, including the general public, as advancing a set of strategic priorities and can clearly demonstrate progress towards clear goals - was, with limited exceptions, pervasive across interviewees. As such, in addition to the emergence of a hybrid model, findings here suggest that "high stakes grantmaking" practices may also be on the rise.

In this conception, high stakes grantmaking involves more than just setting and reaching measurable outcomes and reflecting an emphasis on measurement-driven accountability mechanisms. It also pins success of the foundation against its objectives on grantees adopting the metrics and measurable indicators valued by the foundation, aligning to the foundation's policies and practices, and, in some respects, adopting a theory of action that is complementary to that of the foundation. These practices are high stakes both for the foundation, which links its accountability to the actions of grantees and, to some degree, the audience grantees serve, and for grantees, which rely on funding from foundations in order to operate. The employment of such practices seems most linked to an emphasis on outcomes-oriented approaches, with Appleton, Birchwood, and Crescent displaying the highest tendencies toward high stakes grantmaking. The reliance on high stakes grantmaking has a diffuse impact on other foundation activities, including determination of strategy, selection of grantees, grant applications and proposals, monitoring (i.e. milestone selection and interim reports), and internal program accountability. These remarks from the program officer at Crescent exemplify the centrality of metrics to the grantmaking process:

We have a blanket checklist that is roughly all the things I told you, including what is your student retention, what is your teacher retention, what are your scores, what other scores do you have, if you are doing something other than state test, what are you scoring on it. So they provide that to us ahead of time. If they sent us stuff and it didn't look great and we were so surprised by it because it was a strong organization otherwise, we would work with them to figure out what it is we are missing. But usually because the list we send is so long there is enough and we're relatively sure it is a strong organization anyway at that point, if at the point where they share all that information with us and it doesn't look good, we probably wouldn't be able to move forward but if some of it looks good and some 
of it looks less good, there would probably be more conversation about what else we could include.

Indeed, while Appleton, Birchwood, and Crescent all noted that quantitative measures were not all-determinative of funding decisions and context was very important to determining measures and grants funding, they figured more prominently into the discussion with program officers from those foundations than with those from Silverstone, Tanner, and Vance. However, even on the traditional side, Silverstone and Tanner noted that within the organization, there was concern for how to measure the success of grants and what the right measures are. At Silverstone, it was noted that a large part of conversation with grantees about potential grants focused on "the behaviors, changes, or improvements" that the grantee expected their "work to trigger in others." Thus, even though there was more allowance for the influence of qualitative measures, with Tanner being the most flexible in its thinking on how to evaluate success, there was nonetheless concern for evaluation of quantitative measures in a way that linked the possibility of current and future funding grantees could receive to the means and outcomes of evaluation.

The existence of high stakes grantmaking might be most easily identified in the priorities foundations set with regard to their grantmaking strategies and the impact on grantees. The employment of high stakes grantmaking practices can have a significant impact on shaping other philanthropic activities, including strategy setting. For example, the respondent from Appleton noted that the selection and implementation of shared measurements and evaluation systems was a key objective of the education program:

When we were doing small schools, the main objective was to increase high school graduation rates, and I think that a lot of that work on the policy and advocacy side was to have folks continue to track high school graduation rates and to track it in a common way...I think a big success of our small schools initiative was to get everyone focused on this idea of high school graduation and to use a common measure. As that work progressed, what we found was that even though the country as a whole made huge gains in high school graduation rates, we were still seeing pretty alarming postsecondary matriculation and postsecondary success so when we switched over to our new strategy it was about college readiness. I would say one of the challenges we've had over the last seven years is really to bring folks together to agree on a common metric for what we think as being college ready. Different folks use different measures - ACT, SAT are all things that folks use but no one has really settled on a single metric for college readiness.

These statements indicate a few key aspects of high stakes grantmaking. The first is that it is heavily reliant on the identification of appropriate metrics and measurement tools to gauge success. The second is that acceptance of those metrics and assessments by grantees and other key entities is tantamount to the success of the grants and the initiative overall. The third is the equating of attainment of the goals of the grants (e.g. an $\mathrm{x}$ percentage increase in the high school graduation) as indicative of success, regardless of whether the process to attain them was actually sound. As the respondent's remarks 
indicate, for a grantmaking initiative to become and remain a strategic priority, it must have value as determined by the very metrics is seeks to promote. By that logic then, should the activities of the grantmaking initiative not lead to the measures proving valuable, the initiative would be seen as a failure and no longer be considered a strategy worthy of pursuit.

The second part of high stakes grantmaking, what makes it particularly "high stakes," is the impact it has on grantees. As the program officer from Crescent shared, the demands of funders can have a real impact on the decisions of grantees with respect to determining the kinds of data to capture and how to capture it:

I know for a fact though that in schools sometimes it definitely had to do with funder demands. We have a small independent school in our portfolio that started to get significant institutional funding and started giving their students the state test, not because they felt it was a valuable thing to do but because several funders were asking them for it. They didn't change their educational, and their scores on the test are not that great because they are a progressive school and they don't do any test prep. So I'm pretty sure they only started giving the test because the funders were asking for it.

The program officer voiced a real sense of tension over such practices, recognizing that sometimes it was possible to ask too much of grantees. Indeed, across the foundations interview, particularly Crescent, Silverstone, and Tanner, real concern surfaced over whether such emphasis on measurement and tracking specific metrics placed undue burden on grantees, often times asking them to dedicate resources, both in terms of staff time and technical infrastructure (i.e. procurement of a database), to track the kind of metrics for which foundation ask. Such commitment to measurement was questioned by a number of program officers, particularly from the traditional foundations, who wondered both whether these metrics measured what was most important and if they could ever produce methodologically sound causal conclusions, given the diffuse nature of foundation resources and the work of grantees.

These concerns aside, considering the question of whether high stakes grantmaking practices are a part of the hybrid philanthropy model, the answer appears to be yes, but it is a difference in degrees. As discussed in prior sections, Silverstone and Tanner and, to a lesser extent, Vance, did provide evidence that they utilized measures when making judgments about continuing funding for certain projects and organizations. This was strongest in the case of Silverstone, where the program officer stressed the importance of metrics in determining future funding and ensuring that each grant contributed to the foundation's goals. In the case of Tanner, metrics were secondary to other factors such as the alignment of the organization with the foundation's theory of change and the ability of the foundation to impact other systemic factors through funding a particular grantee. Thus, given the secondary place of metrics to the grantmaking model for many more traditional foundations, the high stakes were in some ways lower.

The data in Tables 3 illustrating convergence around grantees is perhaps the strongest indication that high stakes grantmaking might be part of a hybrid model. As noted, there were 273 organizations that received grants from at least one strategic and one traditional funder. Of those, 28 received grants from at least two strategic and two 
traditional funders. Table 3 shows the top eight organizations that received the most grants. Looking at the top eight organizations, the trend toward directing resources to organizations that are considered data-centered, outcome-oriented, and aligned with funder's advocacy and policy priorities becomes even clearer. Consider New Venture Fund, an organization that acts as a fiscal sponsor for a wide number of organizations, projects, and campaigns in education. Examining the grant descriptions, the vast majority of grants go to supporting funders' preferred policy reforms, such as promotion of the Common Core State Standards and the implementation of standards-based reforms, or organizations that are focused on "data-driven" change and decision making, which aligns nicely with outcomes-oriented approaches to grantmaking. While the organizations that receive these funds are diverse, ranging from National Network of State Teachers of the Year to the Communities for Just Schools Fund, a high proportion of the organizations under New Venture Fund promote or benefit from a strategic capitalist model of grantmaking, such as New School Venture Fund, which received at least five of the grants under the New Venture Fund umbrella.

Moving down the list of top recipients, other organizations represent what "jurisdictional challengers," which are organizations that challenge the dominant regime's claim to control policy domains and the resources of the state as related to those policies (Mehta \& Teles, 2012). In this case, traditional education institutions, such as university teacher preparation programs, research institutions, and public schools and schools systems, are challenged by organizations that offer alternate teacher training and certification, school management models, and producers of knowledge and research (Reckhow \& Snyder, 2014.) Such is the case for KIPP, a charter management organization that operates 242 schools enrolling over 10,000 students nationwide; New Visions for Public Schools, an operator of both traditional district and charter schools serving over 40,000 students; Teach for America, an alternative teacher preparation program; and Harlem Children's Zone, a community support provider that also operates charter schools in New York City. While those organizations challenge traditional providers of teacher education and school operation, The Education Trust challenges traditional sources of research and knowledge. An advocacy and research organization, The Education Trust provides "data-centered" resources on a host of issues, including accountability and college-and-career ready standards and assessments.

Of course, as the hybrid model would suggest, traditional sources of power and long-standing funder preferences are not entirely displaced by new grantmaking practices and preferences. In this instance, we see that amidst the jurisdictional challengers, Teachers College at Columbia University and Harvard University, institutions considered traditional leaders in the production of knowledge and research, still receive support across the foundation spectrum. That being said, it is notable that Harvard and Teachers College each received less than $17 \%$ of the total that Teach for America received over the same time period. Of the $\$ 434$ million received across these eight organizations from 2010 to 2016 , only $10 \%$ went to traditional education institutions; $90 \%$ was distributed to jurisdictional challengers that align to the outcomes-oriented practices of funders. This raises a number of concerns, including to what extent the adoption of high stakes grantmaking may limit to what sorts of organizations, focusing on what kinds of problems and promoting what types of solutions, foundations direct resources. 
I should be clear that the existence of high stakes grantmaking as part of a hybrid model should not be construed as strictly negative. Indeed, the interviews indicated that foundation officers are concerned with being able to show that their grants are contributing to meaningful societal changes and they find that thoughtful approaches to measurement and evaluation help them both demonstrate success and identify areas where they are struggling to do so. On one level, there is the sense that foundations are seeking a way to be internally responsible for grantmaking decisions. As the foundation officer from Silverstone discussed, there are questions from the president and the Board of Directors that surface around every grant, including how does the grant fit into the foundation's theory of change, how does the foundation know if progress is being made in the areas it cares about, and how is that progress being measured. On another level, there is a sense that foundations are seeking to justify their choices to external stakeholders, including grantees, other foundations, and the general public. As the foundation officer at Tanner expressed, there is a sense of urgency that foundations and those setting the funding agenda be able to immediately justify their choices, or else risk losing the confidence of Boards that "then switch attention, hire new presidents and CEOs, and ask them to change things up completely."

However, there is reason to doubt that measurable outcomes as part of high stakes grantmaking serves as an accurate and effective means of holding the foundation as an institution accountable for its grantmaking. While the remarks from the foundation officer at Birchwood suggested that there might be linearity - an ability to roll up results from the grant level to the program level and the whole foundation level-even the larger strategic philanthropies recognized the limitations, as evidenced by these reflections by a program officer of Appleton:

I think it goes back to this tension around the length of the grant versus the kinds of outcomes that we're hoping to see. We have this long-term view in terms of the grants and the ultimate outcome, but our grants are very short-term in nature. It is really hard to build that long-term measurement view when part of the grant is still about learning and adjusting along the way. Even from an evaluation standpoint, the methods being used aren't that rigorous and so while I think we've learned things, overall we're not very good at it.

This echoes what both consultants said around what is perhaps the pair of elephant in the room with respect to measurement: 1) To what extent are measurable outcomes and metrics actually useful and able to gauge the discrete success of foundations and, particularly in the case of large national funders, the achievement of ambitious strategic objectives; and 2) How feasible is this given the generally short-term nature of grants and, in many cases, foundation strategic initiatives? Amongst the many problems that this presents, the biggest is attribution. By attribution, I mean that given that even the largest foundation resources are small and, in most cases, short-lived compared to public sector dollars, and given that the problems of public education are large, multifaceted, and complex, with many actors working to different ends in different places to address them, how can foundations actually identify any shifts against any measures as ultimately attributable to their actions? The program officer from Tanner, echoing similar statements from his colleagues, seems to identify this tension: 
There are a lot of things you could say are correlated, but causality probably doesn't even exist in the social sciences. Then to say that philanthropy is causing changes that's even harder to measure. So, for us, the primary objective is how are policy conditions and the conditions on the ground changing? And to what degree can we say that our grantmaking has helped facilitate, accelerate, amplify and shift power to groups on the ground to make those changes happen?

The challenge of identifying and assigning causality is raised by one of the consultants and is a problem for which he provides some guidance:

I think that they should just have a realistic assessment of the relationship between their goals, their resources, and the objectives for success that they announce. You have some foundations that have massive strategic objectives, significant resources but not that significant compared to the total public resources that are being committed to their issue area. However, they then that also develop these very ambitious measures that just can't be achieved. So if you want to have more ambitious strategic objectives, then you probably honestly need less ambitious specific measures because you are trying to change complex systems at a very large scale.

Based on his assessment then, there would appear to be three options that might ultimately suggest ways of addressing these. The first is prioritizing contribution over attribution. If a large purpose of accountability mechanisms in foundations, as surfaced by the interviews, is to identify the extent to which grantmaking has led to the achievement of progress against program objectives, then an accounting of how foundation dollars have contributed to observed changes against selected measures might be more suitable. Contribution bypasses the need to evaluate for causality as it precludes the need to isolate a foundation's specific dollars from another, which can be problematic when multiple funders support an organization or an initiative and can't necessarily trace what their dollars do as opposed to another. A second option is that, should attribution be preferred, foundations might consider narrowing their focus to be specific not only in where they fund but also what they fund. In other words, for a foundation to claim that their dollars led to the attainment of specific outcomes, they should direct funding to a specific place or objective. A final option is to think strategically at a very high level about where the foundation is best positioned to influence the system, adopt realistic expectations about what its funding can achieve, and then seek out grantees that either fit with the foundation's thinking, thereby enabling the foundation to gauge success as directly related to the work of the grantee, or can help shape the foundation's future strategy. This sort of trend towards realism is perhaps best embodied by the comments from the program officer at Tanner:

We work on inequality, and I was asked the other day, "Shouldn't we be tracking Gini coefficients at the country level?" To which my thinking was, "How effective do you think we are?" We're talking about very small amounts of money in many of the countries in which we work. We spend pretty much the same amount in India, Nepal, and Sri Lanka combined as we do in Detroit, which is about $\$ 12$ or 
$\$ 13$ million. We have to be really realistic about what it is we can achieve. To do that, we try to stay at the systems level and figure out where the pressure points around inequality. When we're really strategic about that, we can actually have some impact, but we have to be really pragmatic about what can be achieved.

Even so, it must be acknowledged that the presence of any stakes inherently in tension with an emphasis on building an ecosystem marked by heterogeneity of organizations. It is fair to say that shifting an ecosystem is substantially harder than changing a single grantee, and should the ecosystem reject the change, it is much more difficult to assign responsibility to any individual organization. Thus, if the trend across the organizational field is to move towards this hybrid model that encompasses a high stakes grantmaking approach, consideration of how best to gauge success becomes even more central within these organizations. Otherwise, the tension within and between philanthropies and between them in terms of how they assess the success of their grantees and, in turn, evaluate their own impact across an ecosystem will persist.

\section{Implications \& Further Considerations}

Foundations and their leadership exert considerable effort thinking about their grantmaking practices, examining priorities based on empirical evidence and feedback, and altering strategies to maximize their influence (Hess \& Henig, 2015). The respondents in this study demonstrate a commendable commitment to those practices of reflection, introspection, and constant learning and improvement. In the area of measurement and evaluation, philanthropies both new and old and across the size, geographic, and wealth spectra have grappled with how to assess alignment between grantee and foundation theories of change, incorporate meaningful metrics and create processes that enable evaluation of their impact and promote accountability.

I find here that while research to date has effectively identified points of divergence between traditional and strategic philanthropies, it overlooks critical ways in which the grantmaking practices of traditional philanthropies have fundamentally shifted in the age of strategic capitalist models of giving, and the ways in which strategic philanthropies have incorporated some of the practices of traditional philanthropies. This convergence can be attributed to a number of causes, including institutional demands and homogenization of the organizational field, as institutional isomorphism would suggest, and awareness of the complex contexts in which they and their grantees operate. The result of this isomorphic pressure is the emergence of a hybrid philanthropy model. The interviews I conducted yielded some evidence to indicate the movement of both traditional and strategic philanthropies toward such a model. While measurable outcomes and metrics, trademarks of the outcomes-oriented grantmaking characteristic of strategic philanthropies, remain critical to the grantmaking approaches of many foundations, there is evidence to suggest that both traditional and strategic philanthropies are having an influence on each other's discourse, resulting in an emerging shared framework for grantmaking that extends beyond just metrics to include an emphasis on field-oriented practices. In particular, this includes building the capacity of grantee organizations and connecting grantees to each other to strengthen the field, taking on a mindset that centers building up systems and policy ecologies. 
I further posit that, as a result of the spread of strategic philanthropic models and larger public policy trends, a wide variety of foundations are now exercising what might be termed "high stakes grantmaking," whereby they make grants based on the adoption of particular measures and achievement of predetermined results on the part of grantees. While the hybrid philanthropy model is not solely outcomes driven, the pre-occupation with data-driven decisionmaking in the field of education means that high stakes grantmaking can have serious implications for the field. As Reckhow (2016) has shown, the desire to pursue certain policy priorities and activities through grantmaking has a real impact on which organizations received funding. This research extends the work, finding that the decision to select and fund organizations that can mold to the priorities of the grantmaking process set by a foundation can have equally limiting outcomes on which organizations receive funding and what policy problems and solutions are deemed worthy of foundation support. Thus, while the focus on expanding systems and ecological conceptions of change could potentially change the profile of grantees, there is an inherent tension with high stakes grantmaking practices that lends itself to continuing to fund at the highest levels those that appear positioned to meet high measurable outcomes.

There are clear political and policy implications for this work. On one level, there are implications for foundations and those who advise them. As discussions with one of the consultants indicated, there is a clear tradeoff between how broadly a foundation can set the objectives of its strategy and its ability to measure impact. As this study reveals, foundations, particularly larger ones that operate on a national level and have significantly more resources compared to others, clearly feel compelled to say that their work is going to achieve significant, measurable results, even if the achievement of those goals is not feasible in the first place. However, as one consultant pointed out, accountability to whom and for what remain unanswered questions for most foundations, and in many ways, hinders them from taking risks with what they fund and thinking more creatively about how they can measure success.

In light of that, the question remains as to how foundations might change mindsets and practices to align with a more realistic approach to measurement and metrics that allows for some internal accountability (e.g. to a Board of Directors or living benefactor) but does not place an undue burden on grantees. The best way, as revealed by this research, might be for foundations to think about gauging the success of initiatives as one of contribution, not attribution. Foundations might find it more authentic to track results at a higher level and note how the foundation's investments might have contributed to changes in areas of interest (e.g. how did a particular reform movement to which the foundation contributed progress). This is fundamentally different from attribution, where foundations seek to directly link changes in the field to the dollars they invested. However, as already noted, the intersectionality of education with so many other fields and the complicated political, social, and economic contexts in which grantees operate and children learn makes such attribution difficult. Given the problems presented by many measurement tools, accounts of grant success tend to be impressionistic anyway. In such circumstances, an emphasis on highlighting contribution over attribution is more realistic and methodologically feasible.

That being said, for smaller foundations operating in a specific location and focused on grantmaking in niche areas, it could be more feasible to assess the impact of grantmaking through measurable outcomes and metrics and arrive at attribution. For 
larger foundations seeking to find meaningful ways to use quantitative assessment to attribute sector change to grantmaking, there could be opportunities in instances where the foundation has targeted, place-based initiatives and/or dollars are directed towards grantees working on a very discrete set of objectives. Longevity of strategy also helps. As one consultant put it, foundations that focus on a discrete number of issues and take the long view with respect to goal attainment, thinking about the fulfillment of their objectives as a long game that takes years to achieve, might find it easier to trace the impact they are having on the field over time. Undoubtedly, complications specific to the risks inherent in every distinct context will arise. Nonetheless, the ability for metrics to contribute meaningful insight on foundation success would be enhanced in a defined space, whether those definitions are geographic, issue specific, or the term length of grants.

There are limitations to the study presented here that yield suggestions for further research. First, only six foundations were included, the majority of which were national in scope. This means that there are limits to the extent that this might be applicable in the case of, for example, smaller foundations that focus on more discrete issues and are very place-based in their funding. That does not mean that the theories proposed here do not apply; the convergence exhibited by Vance and Crescent with philanthropies both similar and different to them indicates that the theories may have wide ranging applicability across foundations of different sizes and geographic foci. What it does mean though, as has been discussed, is that the ability to effectively set measurable outcomes, track the success of foundation strategies, and, ultimately, attribute any progress in targeted areas to philanthropic efforts may be more manageable, provided the foundation has resources to engage in such an undertaking. In any case, the limitations in size and scope of the foundation's funding may change how they might think about the importance of measurable outcomes and metrics in their own context.

Another limit is the extent to which this research does not capture high stakes grantmaking practices as experienced by grantees. As I stated at the beginning, due to the reliance of non-profit organizations on philanthropic dollars to sustain themselves, the high stakes also contribute to pressure to hit the measures as experienced by current and prospective grantees seeking funding opportunities. There may even be high stakes as grantees make choices that align to their fundraising and development needs but may or may not be consistent with the needs of clients and constituents (i.e. schools, school districts, students, and parents). Finally, there remain questions as to what happens to grantees and their constituents in the event that foundations no longer consider them valuable investments based on a failure to hit measurable outcomes. Subsequently, to get at these aspects of high stakes grantmaking, it would be useful to select specific grants and understand why they were not renewed and the impact that had on schools and education more broadly. Furthermore, it would be useful to interview grantees to understand how they perceived foundation grantmaking preferences. Upon what did the grantees understand renewal funding to be predicated? How did receiving funding impact their business model and practices? Did they make different decisions because of the grants? What was the impact on the community, including students and families, as a result of these grants? These are all questions for further research.

Foundation involvement in urban education policy does not occur in a vacuum, and as a result, the choices made by foundations with respect to their grantmaking 
practices at once respond to and produce political consequences. In today's political and education policy context, how to determine, measure, and evaluate outcomes is a topic of much debate. Subsequently, as political actors with real influence on actors at multiple levels of the public education system, how foundations choose to measure and evaluate their strategies and those of their grantees can have reverberating effects. This research begins to examine these relationships; further research in the areas previously discussed would be instrumental in continuing to monitor trends and identify the impact of foundations on education policy. 


\section{Tables}

Table 1: Selected Foundation Characteristics

\begin{tabular}{|l|l|l|l|l|l|}
\hline Foundation & $\begin{array}{l}\text { Geographic } \\
\text { Focus }\end{array}$ & Type & $\begin{array}{c}\text { Traditional/ } \\
\text { Strategic }\end{array}$ & $\begin{array}{c}\text { Total assets } \\
(2017, \text { market } \\
\text { value })\end{array}$ & $\begin{array}{c}\text { Total annual } \\
\text { giving }(2017)\end{array}$ \\
\hline $\begin{array}{l}\text { Appleton } \\
\text { Foundation }\end{array}$ & National & IN & Strategic & $>\$ 5,000,000,000$ & $>\$ 600,000,000$ \\
\hline $\begin{array}{l}\text { Birchwood } \\
\text { Foundation }\end{array}$ & National & IN & Strategic & $\begin{array}{l}\$ 1,000,000,000- \\
\$ 5,000,000,000\end{array}$ & $\begin{array}{l}\$ 350,000,000- \\
\$ 600,000,000\end{array}$ \\
\hline $\begin{array}{l}\text { Crescent } \\
\text { Foundation }\end{array}$ & $\begin{array}{l}\text { Local - } \\
\text { urban }\end{array}$ & IN & Strategic & $<\$ 1,000,000,000$ & $<\$ 100,000,000$ \\
\hline $\begin{array}{l}\text { Silverstone } \\
\text { Foundation }\end{array}$ & National & IN & Traditional & $\begin{array}{l}\$ 1,000,000,000- \\
\$ 5,000,000,000 *\end{array}$ & $\begin{array}{l}\$ 100,000,000- \\
\$ 349,999,999 *\end{array}$ \\
\hline $\begin{array}{l}\text { Tanner } \\
\text { Foundation }\end{array}$ & National & IN & Traditional & $>\$ 5,000,000,000$ & $\begin{array}{l}\$ 350,000,000- \\
\$ 600,000,000\end{array}$ \\
\hline $\begin{array}{l}\text { Vance } \\
\text { Trust }\end{array}$ & $\begin{array}{l}\text { Local - } \\
\text { urban }\end{array}$ & $\mathrm{CM}$ & Traditional & $\begin{array}{l}\$ 1,000,000,000- \\
\$ 5,000,000,000\end{array}$ & $\begin{array}{l}\$ 100,000,000- \\
\$ 349,999,999\end{array}$ \\
\hline
\end{tabular}

Type (of Foundation): IN= Independent Foundation; CM=Community Foundation.

*FY ending 2015-09-30

Table 2: Overview of Selected Foundations Awarding Grants to Recipients Elementary and Secondary Education, United States, 2010-2016

\begin{tabular}{|l|c|c|l|}
\hline Foundation Name & No. of Grants & No. of Recipients & Dollar Value of Grants \\
\hline Appleton Foundation & $>2,000$ & 800 & $>\$ 1,000,000,000$ \\
\hline Birchwood Foundation & $1,000-2,000$ & 1,000 & $>\$ 1,000,000,000$ \\
\hline Crescent Foundation & $<500$ & 60 & $<\$ 100,000,000$ \\
\hline Silverstone Foundation & $<500$ & 200 & $\begin{array}{l}\$ 100,000,000- \\
\$ 500,000,000\end{array}$ \\
\hline Tanner Foundation & & & $\begin{array}{l}\$ 100,000,000- \\
\$ 500,000,000\end{array}$ \\
\hline Vance Trust & $<500$ & 250 & $<\$ 100,000,000$ \\
\hline
\end{tabular}

Source: The Foundation Center ("Foundation Center," n.d.). 
Table 3: Top 8 organizations funded across strategic and traditional philanthropies, 20102016

\begin{tabular}{|l|l|l|l|l|}
\hline Organization & $\begin{array}{l}\text { Total amount } \\
\text { of grants }(\$)\end{array}$ & $\begin{array}{l}\text { Total number } \\
\text { of grants }(\#)\end{array}$ & $\begin{array}{l}\text { Number of } \\
\text { strategic } \\
\text { philanthropies }\end{array}$ & $\begin{array}{l}\text { Number of } \\
\text { traditional } \\
\text { philanthropies }\end{array}$ \\
\hline New Venture Fund & $\$ 122,000,000$ & 68 & 2 & 2 \\
\hline KIPP & $\$ 74,000,000$ & 67 & 3 & 2 \\
\hline Teach for America & $\$ 130,000,000$ & 67 & 3 & 3 \\
\hline $\begin{array}{l}\text { New Visions for } \\
\text { Public Schools }\end{array}$ & $\$ 22,000,000$ & 45 & 2 & 3 \\
\hline $\begin{array}{l}\text { President and } \\
\text { Fellows of } \\
\text { Harvard College }\end{array}$ & $\$ 22,000,000$ & 41 & 2 & 3 \\
\hline Education Trust & $\$ 37,000,000$ & 32 & 2 & 2 \\
\hline $\begin{array}{l}\text { Harlem's Children } \\
\text { Zone }\end{array}$ & $\$ 5,000,000$ & 26 & 2 & 3 \\
\hline $\begin{array}{l}\text { Teachers College, } \\
\text { Columbia } \\
\text { University }\end{array}$ & $\$ 22,000,000$ & 25 & 2 & 2 \\
\hline
\end{tabular}

\section{References}

Charmaz, K. (2006). Constructing grounded theory: A practical guide through qualitative analysis. Los Angeles: Sage Publications.

DiMaggio, P. \& Powell, W. (1983). The iron cage revisited: institutional isomorphism and collective rationality in organizational fields. American Sociological Review, 48, 147-160.

Forti, M. (2012). Six theory of change pitfalls to avoid. Stanford Social Innovation Review.

Hess, F. (Ed.). (2005). With the best of intentions: how philanthropy is reshaping $\mathrm{K}-12$ education. Cambridge: Harvard Education Press.

Hess, F., \& Henig, J. (Eds.). (2015). The new education philanthropy: politics, policy, and reform. Cambridge: Harvard Education Press.

Huerta, L. \& Zuckerman, A. (2009). An institutional theory analysis of charter schools: addressing institutional challenges to scale. Peabody Journal of Education, 84(3), 414-431.

Mehta, J. \& Teles, S. (2012). Jurisdictional politics: a new federal role in education. In F. Hess, Carrots, sticks, and the bully pulpit: lessons from a half-century of federal efforts to improve America's schools. Cambridge: Harvard Education Press.

Merriam, S. (2009). Qualitative research: A guide to design and implementation. San Francisco, CA: Jossey-Bass.

Merriam, S., \& Tisdell, E. (2016). Qualitative research: A guide to design and implementation (4 ${ }^{\text {th }}$ ed.). San Francisco: Jossey-Bass. 
Meyer, J., Scott, R., and Deal, T. (1983). Institutional and technical sources of organizational structure: explaining the structure of educational organizations. In J. Meyer \& R. Scott (Eds.), Organizational environments: ritual and rationality (p. 45-67). Sage Publications.

Reich, R. (2016). Repugnant to the whole idea of democracy? On the role of foundations in democratic societies. Politics Symposium, 466-471.

Reckhow, S. (2010). Disseminating and legitimating a new approach: the role of foundations. In K. Bulkley, J. Henig, \& H. Levin (Eds.), Between public and private: politics, governance, and the new portfolio models for urban school reform. Cambridge: Harvard Education Press.

Reckhow, S. (2013). Follow the money: how foundation dollars change public school politics. New York, NY: Oxford University Press.

Reckhow, S., \& Snyder, J. (2014). The expanding role of philanthropy in education politics. Educational Researcher, 43(4), 186-195.

Reckhow, S. (2016). More than policy patrons: how foundations fuel policy change and backlash. Politics Symposium.449-454.

Russakoff, D. (2016). The prize: who's in charge of America's schools? Boston: Mariner Books.

Sands, S. (2019). Applying a rational systems approach to the analysis of education philanthropies' grantmaking practices. New York State Political Science Association (NYSPSA). Staten Island, NY: April. Paper presentation.

Scott, J. (2009). The politics of strategic philanthropy in charter school policy and advocacy. Educational Policy, 23(1), 106-136.

Snyder, J. (2015). How old foundations differ from new foundations. In F. Hess \& J. Henig (Eds.), The new education philanthropy: politics, policy, and reform (p. 29-53). Cambridge: Harvard Education Press.

Tompkins-Stange, M. (2013). "Big think" or "bottom up"? How private philanthropic foundations seek to influence public education policy (Doctoral dissertation). Retrieved from ProQuest.

Tompkins-Stange, M. (2016). Policy patrons: philanthropy, education reform, and the politics of influence. Cambridge: Harvard Education Press. 